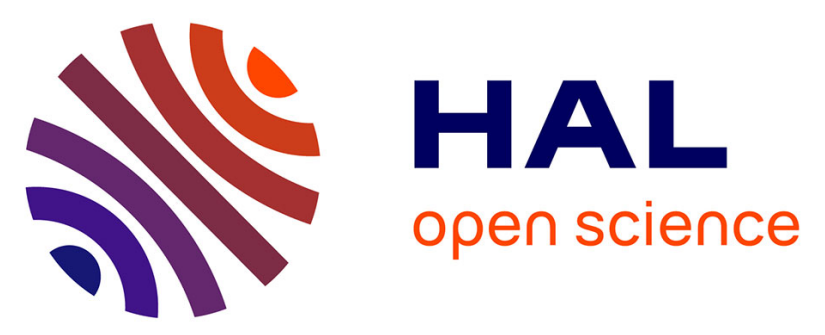

\title{
Longitudinal investigation of Salmonella spp. from farm to fork in the pig industry in Reunion Island
}

\author{
Claire Tessier, Laura Atiana, Eric Cardinale, Martine Denis
}

\section{To cite this version:}

Claire Tessier, Laura Atiana, Eric Cardinale, Martine Denis. Longitudinal investigation of Salmonella spp. from farm to fork in the pig industry in Reunion Island. 10th International Conference on the Epidemiology and Control of Biological, Chemical and Physical Hazards in Pigs and Pork, Sep 2012, Portland, United States. hal-01162546

\section{HAL Id: hal-01162546 \\ https://hal.science/hal-01162546}

Submitted on 5 Sep 2015

HAL is a multi-disciplinary open access archive for the deposit and dissemination of scientific research documents, whether they are published or not. The documents may come from teaching and research institutions in France or abroad, or from public or private research centers.
L'archive ouverte pluridisciplinaire HAL, est destinée au dépôt et à la diffusion de documents scientifiques de niveau recherche, publiés ou non, émanant des établissements d'enseignement et de recherche français ou étrangers, des laboratoires publics ou privés. 


\title{
Longitudinal investigation of Salmonella spp. from farm to fork in the pig industry in Reunion Island
}

Tessier C *, ${ }^{(1,2)}$, Atiana, L. ${ }^{(2,3)}$, Cardinale, E. ${ }^{(2,3)}$, Denis, M. ${ }^{(4,5)}$

(1) Coopérative des producteurs de porcs de la Réunion, Saint Pierre, Réunion

(2) Centre de coopération internationale en recherche agronomique pour le développement, Sainte Clotilde, Réunion

(3) Centre de Recherche et de Veille dans l'Océan Indien, Saint Clotilde, Réunion

(4) Anses Laboratory of Ploufragan/Plouzané, Unit of Health and Quality of Poultry And Pig Products, BP 53, 22440

Ploufragan, France.

${ }^{(5)}$ European University of Brittany, France.

*corresponding author: ctessier@cppr.fr

\begin{abstract}
Salmonella is, after Campylobacter, the most reported zoonotic pathogen in Europe. Pork meat is frequently incriminated in salmonellosis. However, asymptomatic carrying of Salmonella by pigs makes its detection difficult. Despite its tropical situation, pig industry of Reunion Island is also concerned by this public health burden.
\end{abstract}

Our epidemiological study aims to identify the pathways of contamination along the pig chain industry. Three Salmonella positive farms were followed from the farrowing to the pork cuts. At farm level, Salmonella excretion was detected by individual samples of feces at birth, farrowing, post-weaning and fattening. During slaughtering, samples were taken from pigs entering and from carcasses after polishing, splitting and chilling. Caeca and pork cuts were also collected. Environmental samples of water, food and environment at farm and at different stages before slaughtering and cutting of the day were taken.

Among the 900 analysed samples, 229 isolates were collected and divided into 42 pulsotypes and 12 serotypes. S. monovariant 4,[5],12:i:-, S. Rissen, S. Typhimurium and S. Livingstone were predominant. Three different infection profiles were observed. At the nursing stage, piglets were Salmonella free. Infection occurred either after post-weaning $(2 / 3)$ or during the fattening period (1/3). Truck and lairage are cross-contamination stages (100\% are positive before pig loading). On the contrary, slaughterhouse is a decreasing contamination stage (equipment and pork cuts are Salmonella free). Farm surroundings play a major role in the reinfection of pigs like other animal productions.

This original investigation, made for the first time until now, give an accurate photography of Salmonella spreading along the chain.

\section{Introduction}

Salmonella is one of the main zoonotic pathogens in Europe. Pork meat is frequently incriminated in salmonellosis. Despite being highly studied in poultry production, epidemiological data are missing concerning Salmonella contamination of pork meat in Reunion Island. Limiting Salmonella contamination is dependent on identifying the source and ways of dissemination of Salmonella transmission at each stage during production and during slaughtering.

The aim of this study was to identify the pathways of contamination all along the chain industry of Reunion Island, from the farm to pork cuts.

\section{Material and Methods}

Three farrow-to-finish farms, previously detected Salmonella positive, were selected for this project. Farms were selected from different geographical locations in Reunion Island and with different environmental characteristics and different general husbandry practices. They were monitored from farrowing to the pork cuts. Three sows and 5 piglets by sow were selected from one batch per farm.

At farm level, Salmonella excretion was detected by individual samples of feces, after farrowing and throughout each growing stage. At slaughterhouse level, gauze swabs from pigs entering and from carcasses after polishing, splitting and chilling, caecal contents and pork cuts were sampled. Environmental samples were collected at both farm and slaughterhouse levels.

They were collected at each visit in farms and all along the slaughtering and cutting process at the beginning of the day, before the slaughter of the followed pig batch.

Environmental and feces samples were pre-enriched in buffered peptone water (BPW) in 1:10 sample/broth ratio. Disinfectant neutralizer was added in BPW broth (1:10) for samples collected after cleaning and disinfection. Environmental swabs and socks were pre-enriched with 150 and $300 \mathrm{ml}$ of BPW respectively. After incubation at $37^{\circ} \mathrm{C}$ for $18 \mathrm{~h} \pm 2 \mathrm{~h}$, one $\mathrm{ml}$ and 3 
drops of BPW broth were inoculated respectively to $10 \mathrm{ml}$ of Müller-Kauffmann Tetrathionate-Novobiocin broth (MKTTn) and on Modified Semisolid Rappaport Vassiliadis agar (MSRV) plate. Both were incubated respectively at $37^{\circ} \mathrm{C}$ for $24 \mathrm{~h}$ and $41.5^{\circ} \mathrm{C}$ for $24-48 \mathrm{~h}$. Samples of feed were analysed as described previously. However, selective enrichment was done with MKTTn and Rappaport Vassiliadis Broth (RVB), incubated respectively at $37^{\circ} \mathrm{C}$ and $41.5^{\circ} \mathrm{C}$ for $24 \mathrm{~h}$. A loopful of selective enrichment in MKTTn or RVB was then streaked on Xylose-Lysine-Desoxycholate Agar (XLD) and Rambach Agar. MSRV plates with characteristic halo of migration were streaked onto XLD and Rambach agar. After $24 \mathrm{~h}$ at $37^{\circ} \mathrm{C}$, four typical colonies per sample (one per way if possible) were biochemically confirmed as Salmonella and serotyped according to the Kauffman-White scheme.

\section{Results}

Amongst the 900 analyzed samples, 229 isolates have been collected. They were divided into $42 \mathrm{XbaI}$ pulsotypes and 12 serotypes: monovariant of Typhimurium 4,[5],12:i:- (72), Rissen (60), Typhimurium (32), Livingstone (25), Weltevreden (12), Derby (10), London (8), Senftenberg (3), Newport (3), Bredeney (1), Blockley (1) and Give (1). Some serotypes were predominant in some farms: 4,[5],12:i:- in farm A and B, Rissen in farm B and Typhimurium / Livingstone in farm C. Distribution of pulsotypes in farm B from farrowing to pork cuts is illustrated in Figure 1.

Water, feed, cockroach and rodents samples return all negative.

Although floor of maternity and corridor were positive for Salmonella, neither sows nor piglets excreted Salmonella until the end of nursing $(2 / 3)$.

Piglets started to excrete Salmonella a few weeks after the beginning of post-weaning. Pulsotypes were similar to the ones found in the room after cleaning and disinfection, and in corridor before the beginning of post-weaning stage (2/3).

Afterwards, until the end of pig fattening, pulsotypes were identical to the ones previously found during post-weaning or in farm environment (including other animal productions). For one of the 3 farms, pigs were excreting Salmonella at a late fattening stage whereas, in the other ones, the number of contaminated pigs decreased during the fattening period

Loading bay (2/3), truck (3/3) and lairage room at slaughterhouse (3/3) were contaminated with new pulsotypes. Before slaughtering and cutting, equipment and tools were negative except knives (1/3). However, this pulsotype was not detected in any other sample. At slaughterhouse, just prior to slaughter, pigs were carrying both previously detected pulsotypes and new ones. Some pulsotypes were detected from carcasses after polishing (3/14 for farm B) and after splitting (2/14 for farm $\mathrm{B}$ and 2/15 for farm C). However, all samples collected after splitting steps were negative.

\section{Discussion}

All samples of water, feed, rodents and cockroaches were Salmonella negative. However, Salmonella has ever been isolated from same types of samples (Davies et al., 1997; Letellier et al., 1999) as well as in flies (Khalil et al., 1994), all collected from Salmonella positive farms. These findings may suggest that they play a role in the spread of Salmonella.

None of the sows and none of the piglets were shedding Salmonella during nursing. Kranker et al. (2003) showed that, although some sows were seropositive during nursing, none piglets were Salmonella positive. This finding suggests two explanations. The first one could be that sows play a minor role in Salmonella contamination of pigs during growing. And the second one that passive maternal immunity of sows may have protected pre-weaned pigs from Salmonella contamination (Wales et al., 2009). Moreover, maternal antibodies secreted in colostrum and milk could protect piglets against colonisation by different Salmonella serotypes (Funk et al., 2001).

No piglets were excreted Salmonella before weaning and pulsotypes isolated from piglets and from residual infection were similar. These results confirm that horizontal transmission may be due to residual contaminations (Kranker et al., 2003; Wales et al., 2009).

Contamination of pens in farms studied after cleaning and disinfection is not surprising. Several studies have shown that cleaning and disinfecting pig house is recognized as a challenge (Magistrali et al., 2008; Wales et al., 2009). Moreover, Salmonella can persist outside animals for days to months, and is able to adapt himself to host but also to farm environment (Berends et al., 1996). 
Salmonella was isolated from cleaned truck suggesting that procedures for cleaning and disinfecting was not enough efficient to eliminate Salmonella. Same findings were already shown by (Swanenburg et al., 2001). Lairage room was also positive before arrivals of pigs. Similar pulsotypes were isolated from truck and lairage room before loading and further on back of pigs, from carcasses after polishing and splitting and from caecal contents. This confirms that transport and lairage are important stages of cross-contamination (Magistrali et al., 2008; Bolton et al., 2013). No Salmonella was detected after splitting. This suggests that slaughter process reduce Salmonella contamination, notably after chilling. However, prevalence after this step could be underestimated, because a formation of an ice layer on the carcasses after chilling (Swanenburg et al., 2001). Despite no pork meat were Salmonella positive, we cannot conclude that there is not a risk for consumer.

\section{Conclusion}

This investigation allows us to identify sources of Salmonella contamination at production and slaughterhouse stage. However, characterisation of all isolates per samples could confirm ways of contamination highlighted or to identify new ones. Indeed, individuals may be infected simultaneously with different serotypes (Funk et al., 2001). MLVA on $S$. Typhimurium and $S$. 4,[5],12,:i:- is in progress and will clarify the ways of contamination, indeed, the origin of some pulsotypes have not yet been identified.

\section{Acknowledgements}

We thank the three pig farmers for their active co-operation in this investigation.

\section{References}

Berends, B.R., Urlings, H.A.P., Snijders, J.M.A., Van Knapen, F., 1996, Identification and quantification of risk factors in animal management and transport regarding Salmonella spp. in pigs. International Journal of Food Microbiology $30,37-53$.

Bolton, D.J., Ivory, C., McDowell, D., 2013, A study of Salmonella in pigs from birth to carcass: serotypes, genotypes, antibiotic resistance and virulence profiles. Int J Food Microbiol 160, 298-303.

Davies, P.R., Morrow, W.E., Jones, F.T., Deen, J., Fedorka-Cray, P.J., Harris, I.T., 1997, Prevalence of Salmonella in finishing swine raised in different production systems in North Carolina, USA. Epidemiol Infect 119, 237-244.

Funk, J.A., Davies, P.R., Nichols, M.A., 2001, Longitudinal study of Salmonella enterica in growing pigs reared in multiplesite swine production systems. Vet Microbiol 83, 45-60.

Khalil, K., Lindblom, G.B., Mazhar, K., Kaijser, B., 1994, Flies and water as reservoirs for bacterial enteropathogens in urban and rural areas in and around Lahore, Pakistan. Epidemiol Infect 113, 435-444.

Kranker, S., Alban, L., Boes, J., Dahl, J., 2003, Longitudinal Study of Salmonella enterica Serotype Typhimurium Infection in Three Danish Farrow-to-Finish Swine Herds. Journal of Clinical Microbiology 41, 2282-2288.

Letellier, A., Messier, S., Quessy, S., 1999, Prevalence of Salmonella spp. and Yersinia enterocolitica in finishing swine at Canadian abattoirs. J Food Prot 62, 22-25.

Magistrali, C., Dionisi, A.M., De Curtis, P., Cucco, L., Vischi, O., Scuota, S., Zicavo, A., Pezzotti, G., 2008, Contamination of Salmonella spp. in a pig finishing herd, from the arrival of the animals to the slaughterhouse. Research in Veterinary Science 85, 204-207.

Swanenburg, M., van der Wolf, P.J., Urlings, H.A., Snijders, J.M., van Knapen, F., 2001, Salmonella in slaughter pigs: the effect of logistic slaughter procedures of pigs on the prevalence of Salmonella in pork. Int J Food Microbiol 70, 231-242.

Wales, A.D., McLaren, I.M., Bedford, S., Carrique-Mas, J.J., Cook, A.J., Davies, R.H., 2009, Longitudinal survey of the occurrence of Salmonella in pigs and the environment of nucleus breeder and multiplier pig herds in England. Vet Rec 165, 648-657. 


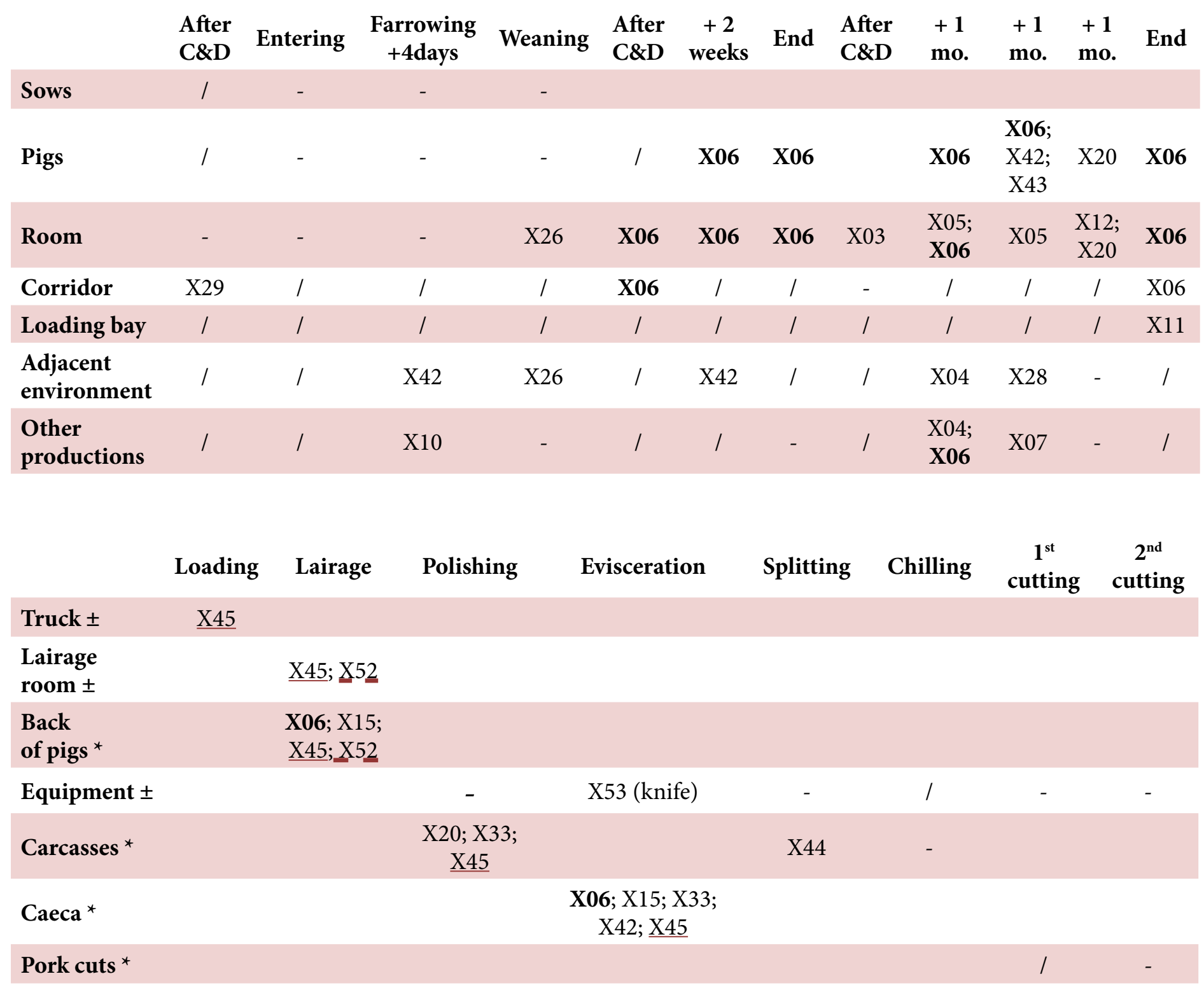

Figure 1: Distribution of Salmonella pulsotypes detected along the investigation in farm $B$ from farrowing to pork cuts C\&D: Cleaning and disinfection. /: not done. -: negative sample. ${ }^{*}$ : sampled after step indicated in the arrow. \pm : sampled before step indicated in the arrow. Pulsotypes X03, X04, X05, X06, X07, X10, X12, X20 are S. 4,[5],12,:i:-; X15, X26, X28 and $\mathrm{X} 29$ are $S$. Typhimurium; X33 is $S$. Rissen; X42, X43 and X44 are S. Livingstone; X45 is S. Derby; X52 is S. London and X53 is $S$. Bredeney. X06 (in bold) is a predominant pulsotype. X45 and X52 (underlined) are pulsotypes identified from truck and lairage room and detected on carcasses. 